\title{
Develando la sexualidad en la gestante
}

\author{
Unveiling sexuality in the pregnant woman
}

\author{
Gema Sologuren-García ${ }^{\text {1a }}$, Carmen L. Linares ${ }^{1 \mathrm{a}}$, Jackeline R. Flores ${ }^{\text {1b }}$ \\ ${ }^{1}$ Escuela Profesional de Obstetricia. Facultad de Ciencias de la Salud. Universidad Nacional Jorge Basadre Grohmann. \\ Tacna, Perú. \\ ${ }^{a}$ Obstetra con doctorado. \\ ${ }^{\mathrm{b}}$ Licenciada en Obstetricia. Egresada de Maestría en Docencia Universitaria.
}

\begin{abstract}
Resumen
Introducción: El embarazo genera cambios fisiológicos, hormonales y psíquicos condicionados por aspectos socioculturales que pueden afectar la sexualidad; por tanto, es necesario establecer su vivencia según trimestres de gestación. El objetivo fue conocer la sexualidad en las gestantes atendidas en un hospital de Tacna. Material y métodos: Estudio retrospectivo, transversal, con datos secundarios y con una muestra de 346 puérperas atendidas durante el año 2018 en el Servicio de Maternidad del hospital Hipólito Unanue de Tacna. Se aplicó un cuestionario adaptado con 47 ítems según: datos sociodemográficos, información, creencias y datos sobre vivencia de la sexualidad según trimestres. Resultados: Edad promedio 26 años; $46.6 \%$ con instrucción secundaria; el 80.9 \% son convivientes; edad promedio del primer encuentro sexual 18 años; el $39.6 \%$ tuvo dos parejas. El $49.4 \%$ recibió información superficial sobre sexualidad; $67.9 \%$ creen que los encuentros sexuales dañan al feto, y el $55.5 \%$ dice que se puede tener encuentros sexuales hasta un mes antes del parto. Deseo sexual oscilante: poco intenso (41.3\%); medianamente intenso (50 \%), y nuevamente poco intenso $(27.7 \%)$ durante el primer, segundo y tercer trimestre respectivamente. Frecuencia de los encuentros sexuales: una vez por semana fluctuando entre $54.3 \%$; el $42.5 \%$ y $63 \%$ primer, segundo y tercer trimestre respectivamente. El coito peneano vaginal fue la principal práctica erótica: primer trimestre $(87.9 \%)$, segundo (78 \%); y tercero (81 \%) la estimulación mutua. Posturas sexuales "la mujer encima" (al inicio) y "de costado" (intermedio y final). Placer sexual se logró: primer trimestre, $76.3 \%$; segundo, $61.6 \%$, y tercero, el $84.7 \%$. Conclusiones: La vivencia de la sexualidad cambió durante la gestación. Las principales prácticas eróticas fueron el coito peneano vaginal y la estimulación mutua; la postura más practicada fue "de costado" en el último trimestre. El placer sexual se alcanzó mayoritariamente en el tercer trimestre.
\end{abstract}

Palabras clave: Embarazo, sexualidad, vivencia.

\begin{abstract}
Introduction: Pregnancy generates physiological, hormonal and psychic changes conditioned by sociocultural aspects that can affect sexuality; therefore, it is necessary to establish their experience according to gestation trimesters. The aim of this report was to learn about the sexuality of pregnant women cared for in a hospital in Tacna.

Methodology: Retrospective, cross sectional study, with secondary data and with a sample of 346 puerperal women, during 2018 in the Maternity Service of Hipolito Unanue hospital in Tacna an adapted questionnaire of 47 items was applied according to: sociodemographic data, information, beliefs and data on the experience of sexuality according to trimesters.

Results: 26 year old average; $46.6 \%$ secondary education; $80.9 \%$ live in partner; average age of the first sexual encounter 18 year old; $39.6 \%$ had two partners. The $49.4 \%$ received superficial information about sexuality; $67.9 \%$ believe that sexual encounters harm the fetus, and $55.5 \%$ say that it is possible to have sexual encounters up to a month prior delivery. Oscillating sexual desire: little intense (41.3\%), moderately intense (50\%) and again little intense (27.7 $\%$ ) during the first, second and third trimesters respectively. Frequency of sexual encounters: once a week ranging between $54.3 \%, 42.5 \%$ and $63 \%$ first, second and third trimesters respectively. Vaginal penile coitus was the main erotic practice in the first trimester $(87.9 \%)$; second (78\%) and third (81\%) mutual stimulation. Sexual positions: "the woman on top" (at the beginning) and "on the side" (intermediate and final). Sexual pleasure was achieved in the first trimester $76.3 \%$, in the second $61.6 \%$ and in the third $84.7 \%$.

Conclusions: The experience of sexuality changed during pregnancy. The main erotic practices were vaginal penile coitus and mutual stimulation; the most practiced posture was "sideways" in the last trimesters. Sexual pleasure was mostly achieved in the third trimester.

Keywords: Pregnancy, sexuality, experience.
\end{abstract}




\section{Introducción}

La sexualidad es un aspecto central del ser humano, presente en el ciclo de vida, que involucra afectos, vivencias, erotismo, placer, intimidad, reproducción, entre otros; que enriquece el ámbito personal, familiar y social $(1,2)$. El embarazo origina cambios en la mujer modificando su ser biopsicosexual; en consecuencia altera la función sexual (deseo, respuesta y comportamiento sexual) $(3,4)$. Reportando alteraciones como dispareunia, pérdida del deseo y anorgasmia(3).

\section{Material y métodos}

Se realizó un estudio retrospectivo, transversal. La población fue de 3482 puérperas; el muestreo por conveniencia obteniendo una muestra de 346, atendidas durante el año 2018 en el Servicio de Maternidad del hospital Hipólito Unanue de Tacna, quienes reunieron las siguientes condiciones: edad entre 15 a 45 años, que manifestaron la voluntad de participar en el estudio, puérperas que cursaron embarazos sin patología. Se aplicó un cuestionario adaptado del instrumento de Muñoz MJ. ${ }^{(5)}$, que constó de 45 ítems distribuidos en tres secciones: datos sociodemográficos, información, creencias y datos sobre vivencia de la sexualidad según trimestres de gestación.

\section{Resultados}

De las 346 puérperas encuestadas; la edad promedio fue de 26 años, el $46.6 \%$ tuvo instrucción secundaria, $80.9 \%$ fueron convivientes; el primer encuentro sexual fue en promedio a los 18 años; $39.6 \%$ tuvo dos parejas sexuales, y el $58.1 \%$ es primípara.
Se observa que el 49.4\% recibió información superficial sobre sexualidad durante la gestación y el $35.6 \%$ no la recibió; el $32.1 \%$ cree que los encuentros sexuales sí dañan al feto; el $55.5 \%$ dice que se pueden tener encuentros sexuales hasta un mes antes del parto, y solo el $13.9 \%$ hasta el fin de la gestación.

Durante el primer trimestre, el $41.3 \%$ tuvo un deseo sexual poco intenso, y solo muy intenso el $6.9 \%$. En el segundo trimestre, el $50 \%$ lo experimentó medianamente intenso, y el $18.8 \%$ no tuvo. En el tercer trimestre, el $27.7 \%$ lo tuvo poco intenso, y $26 \%$ no lo experimentó. El 54.3\% refirió tener un encuentro sexual por semana en el primer trimestre, disminuyendo al $42.5 \%$ en el segundo; para luego incrementarse al $63 \%$ en el tercer trimestre. La principal práctica erótica en el primer trimestre fue el coito peneano vaginal $(87.9 \%)$; en el segundo trimestre estimulación mutua (78\%), que se incrementa al $81.2 \%$ durante el tercer trimestre.

La postura sexual más practicada en el primer trimestre fue "la mujer encima" (25.4\%), "de costado" en el segundo trimestre $(26.9 \%)$ y en el tercer trimestre (27.2\%); llama la atención que el 28\% manifiesta no haber tenido encuentros sexuales. El 46\% señala que "siempre" realizan juegos eróticos en el primer trimestre; el 54\% refiere "nunca" y "a veces"; en tanto, que en el segundo y tercer trimestre lo realizan "a veces" $(73.1 \%$ y $40.8 \%$ respectivamente). En el primer trimestre $43.3 \%$, segundo trimestre $38.4 \%$ y tercer trimestre $33.2 \%$ lubrican su vagina "medianamente fácil", en el segundo y tercer trimestre "no tiene", y fue "nada fácil" para el $47.4 \%$ y $42.8 \%$, respectivamente. El $51.2 \%$ en el primero, $44.8 \%$ en el segundo y $41 \%$ en el tercer trimestre alcanzan el orgasmo "medianamente fácil", el 41.9\% "nunca" y "difícilmente" alcanzarlo durante el primer trimestre. El placer sexual se logra en el primer trimestre en el $76.3 \%$, en el segundo $61.6 \%$ y en el tercero el $84.7 \%$.

Tabla 1. Vivencia de la sexualidad por trimestres de gestación.

\begin{tabular}{lcccccc}
\hline \multicolumn{1}{c}{ Variable } & \multicolumn{2}{c}{ Trimestre 1 } & \multicolumn{2}{c}{ Trimestre 2 } & \multicolumn{2}{c}{ Trimestre 3 } \\
& $\mathbf{N}^{\circ}$ & $\mathbf{\%}$ & $\mathbf{N}^{\circ}$ & $\mathbf{\%}$ & $\mathbf{N}^{\circ}$ & \% \\
\hline Intensidad del deseo sexual & & & & & & \\
No tuvo encuentros sexuales & 52 & 15 & 65 & 18.8 & 90 & 26 \\
Poco intenso & 143 & 41.3 & 90 & 26.0 & 96 & 27.7 \\
Medianamente intenso & 127 & 36.8 & 173 & 50.0 & 92 & 26.6 \\
Muy intenso & 24 & 6.9 & 18 & 5.2 & 11 & 3.2 \\
No responde & 0 & 0 & 0 & 0 & 57 & 16.5 \\
Frecuencia de los encuentros sexuales & & & & & & \\
Una vez a la semana & 188 & 54.3 & 147 & 42.5 & 218 & 63.0 \\
Dos veces a la semana & 95 & 27.5 & 60 & 17.3 & 33 & 9.5 \\
Tres veces a la semana & 39 & 11.3 & 73 & 21.1 & 28 & 8.1 \\
Todos los días & 24 & 6.9 & 13 & 3.8 & 0
\end{tabular}


Diversas eróticas los encuentros sexuales *

Masturbación

Ser estimulada en zonas erógenas

Estimular a mi pareja en zonas erógenas

Estimulación mutua

Recibir coito bucal

Dar coito bucal

Coito bucal mutuo

Coito peneano vaginal

Coito anal

Uso de juguetes sexuales

$\begin{array}{cccccc}79 & 22.8 & 71 & 20.5 & 40 & 11.6 \\ 250 & 72.3 & 228 & 65.9 & 180 & 52.0 \\ 237 & 68.5 & 233 & 67.3 & 276 & 79.8 \\ 238 & 68.8 & 270 & 78.0 & 281 & 81.2 \\ 73 & 21.1 & 70 & 20.2 & 15 & 4.3 \\ 66 & 19.1 & 47 & 13.6 & 125 & 36.1 \\ 48 & 13.9 & 68 & 19.7 & 13 & 3.8 \\ 295 & 85.3 & 262 & 75.7 & 165 & 47.7 \\ 30 & 8.7 & 10 & 2.9 & 7 & 2.0 \\ 9 & 2.6 & 10 & 2.9 & 4 & 1.2\end{array}$

\section{Posturas sexuales utilizadas en los encuentros sexuales}

La mujer encima

La mujer abajo

De costado

De rodillas

De pie

La mujer encima. De costado.

De costado. La mujer abajo.

La mujer encima. De rodillas. La mujer abajo.

La mujer encima. De costado. La mujer abajo.

La mujer encima. De rodillas. De costado. La mujer abajo.

\begin{tabular}{|c|c|c|c|c|c|c|}
\hline La mujer encima & 88 & 25.4 & 45 & 13.0 & 63 & 18.2 \\
\hline La mujer abajo & 81 & 23.4 & 61 & 17.6 & 44 & 12.7 \\
\hline De costado & 49 & 14.2 & 93 & 26.8 & 94 & 27.2 \\
\hline De rodillas & 8 & 2.3 & 11 & 3.2 & 8 & 2.3 \\
\hline De pie & 28 & 8.1 & 11 & 3.2 & 20 & 5.8 \\
\hline La mujer encima. De costado. & 10 & 2.9 & 0 & 0 & 14 & 4.0 \\
\hline De costado. La mujer abajo. & 9 & 2.6 & 18 & 5.2 & 13 & 3.8 \\
\hline La mujer encima. De rodillas. La mujer abajo. & 7 & 2.0 & 20 & 5.8 & 0 & 0 \\
\hline La mujer encima. De costado. La mujer abajo. & 3 & 0.9 & 13 & 3.8 & 0 & 0 \\
\hline $\begin{array}{l}\text { La mujer encima. De rodillas. De costado. La mujer } \\
\text { abajo. }\end{array}$ & 11 & 3.2 & 9 & 2.6 & 0 & 0 \\
\hline No tienen & 52 & 15.0 & 65 & 18.8 & 90 & 26 \\
\hline \multicolumn{7}{|l|}{ Juegos eróticos en el encuentro sexual } \\
\hline Nunca & 31 & 9.0 & 93 & 26.9 & 10 & 2.9 \\
\hline A veces & 156 & 45.0 & 253 & 73.1 & 141 & 40.8 \\
\hline Siempre & 159 & 46.0 & 0 & 0 & 96 & 27.7 \\
\hline No contesta & 0 & 0 & 0 & 0 & 99 & 28.6 \\
\hline \multicolumn{7}{|l|}{ Lubricación vaginal } \\
\hline No tiene & 28 & 8.1 & 66 & 19.1 & 72 & 20.8 \\
\hline Nada fácil & 132 & 38.2 & 98 & 28.3 & 76 & 22 \\
\hline Medianamente fácil & 151 & 43.6 & 133 & 38.4 & 115 & 33.2 \\
\hline Muy fácilmente & 35 & 10.1 & 49 & 14.2 & 16 & 4.6 \\
\hline No contesta & 0 & 0 & 0 & 0 & 67 & 19.4 \\
\hline \multicolumn{7}{|l|}{ Cómo alcanza el orgasmo } \\
\hline Nunca & 36 & 10.4 & 26 & 7.5 & 74 & 21.4 \\
\hline Difícilmente & 109 & 31.5 & 73 & 21.1 & 53 & 15.3 \\
\hline Medianamente fácil & 177 & 51.2 & 155 & 44.8 & 142 & 41 \\
\hline Muy fácilmente & 24 & 6.9 & 39 & 11.3 & 10 & 2.9 \\
\hline No contesta & 0 & 0 & 53 & 15.3 & 67 & 19.4 \\
\hline \multicolumn{7}{|l|}{ Placer sexual } \\
\hline Sí & 264 & 76.3 & 213 & 61.6 & 293 & 84.7 \\
\hline No & 69 & 19.9 & 54 & 15.6 & 53 & 15.3 \\
\hline
\end{tabular}

*Se aceptó más de una respuesta.

8.2

4.3 


\section{Discusión}

Se encontró que, más de las tres cuartas partes de las mujeres encuestadas manifestaron que no recibieron información sobre sexualidad a cargo de un profesional de salud, o lo hicieron de manera superficial. Asimismo, aún existe entre ellas la falsa creencia que los encuentros sexuales pueden dañar al feto. Se observa cierta similitud a los trabajos encontrados por otros investigadores (6). Otro estudio realizado en Colombia mostró significancia estadística entre ideas sobre que las relaciones sexuales le hacen daño al bebé y que estas pueden hacer que el parto se adelante-(7).

Las molestias físicas y el miedo a dañar al feto son las principales razones por las cuales existe variación en la vivencia de la sexualidad durante el embarazo(8).

El deseo sexual durante la gestación se presentó mayoritariamente de poco a medianamente intenso. Llama la atención que en el tercer trimestre muchas mujeres no lo experimentaron. El principio de individualización de la sexualidad, nos permite entender que todos los seres humanos somos únicos, diferentes; por tanto, existe gran variabilidad en cómo este se experimente ${ }^{-}-(2,4,713)$; sin embargo, se ve influenciado, por diversos factores (anatómicos, hormonales, psicológicos, emocionales, socioculturales) (14). Asimismo, puede ser reprimido o postergado, pues el ser humano tiene la capacidad de autorregularlo y controlarlo (2).

La frecuencia de los encuentros sexuales se incrementó en el tercer trimestre de gestación, difiere de los resultados de otras investigaciones que señalan que conforme avanza la gestación disminuyen o están prácticamente ausentes $-(4,7)$. Es preciso señalar que la cantidad de encuentros sexuales es relativa y no determina la vivencia de la sexualidad en pareja; de modo que, la clave radica en su calidad(2,15)

La principal práctica erótica en el primer trimestre fue el coito peneano vaginal. Evidentemente, este es el resultado de la concepción de sexualidad hegemónica y normativa de nuestra sociedad patriarcal, coito falocentrista; a través de las cuales se considera a esta práctica erótica, como la única actividad que permite el disfrute pleno y satisfactorio del encuentro sexual. En el segundo y tercer trimestre se practicó la estimulación mutua, siendo esta una de las múltiples formas de expresar la sexualidad que permite la posibilidad de creatividad y desarrollo de galimatías del juego erótico(2,16,17).

Los resultados mostraron que la postura sexual practicada cambió de un trimestre a otro: "la mujer encima" y posteriormente "de costado" o "de lado". Los estudios muestran resultados similares(9). Son las modificaciones anatomofisiológicas propias de la gestación que causan: aumento del tamaño del útero y dificultad del movimiento; lo que indudablemente hace que la gestante, por comodidad, adopte diferentes posturas a medida que avanza su gestación(10).

Los juegos eróticos mayoritariamente se presentaron a lo largo de la gestación, pero de manera fluctuante; asimismo, un poco más de la mitad refirió que "a veces" o "nunca" lo experimentaron". Otros resultados señalan que en el primer trimestre tuvieron juegos eróticos "la mayoría de las veces", disminuyendo hacia el final de la gestación (11). El desarrollo lúdico de la sexualidad genera beneficios para la salud de la pareja, porque le permite vivenciar el "placer global" y no limitarse al "placer genital" (2).

Las mujeres en estudio lubricaron su vagina "medianamente fácil", disminuyendo en cada trimestre de gestación. Más de la tercera parte manifestaron que "no tienen" lubricación y no es "nada fácil" obtenerla en el tercer trimestre. Distintas investigaciones revelan que la lubricación es menor en el primer trimestre que en el último(12). Desde el punto de vista fisiológico, es sabido que la placenta produce gran cantidad de hormonas aumentando el flujo y lubricación vaginal que favorecen la sexualidad de la pareja $(18,19)$; no obstante, existen factores psicológicos, socio culturales que inhiben o limitan la respuesta sexual(2).

Las gestantes en su mayoría alcanzaron el orgasmo "medianamente fácil", declinando durante el segundo y tercer trimestre. Debemos resaltar que más de la tercera parte refirieron que "nunca" y "difícilmente" lo obtuvieron; otras investigaciones indican que el orgasmo es mayor en el primer trimestre que en el último $(4,12)$. Por otro lado, se muestra que el orgasmo disminuyó en el primer trimestre para luego aumentar en el tercero (20), asimismo la satisfacción también se redujo (8). Diversos autores explican, que la fase orgásmica es más lenta ocasionando contracciones más intensas, debido a la vasocongestión permanente; la sensación de alivio es lenta y no total en la fase de resolución. Es indiscutible que el orgasmo es una de las experiencias más gratificantes; sin embargo, debemos advertir "que considerar al orgasmo como una meta revela una reducción del ejercicio de la sexualidad que genera presión, tensión y una actitud obsesiva por lograrlo, limitando la capacidad de disfrute para el fortalecimiento de la relación de pareja, por lo que es importante valorar el proceso del encuentro sexual"'(2,16).

La vivencia del placer sexual se mostró variable, no obstante, resaltamos que la cuarta parte muestral manifiesta tenerlo durante el tercer trimestre. Otras investigaciones señalan, al respecto, que la actividad sexual durante el embarazo resultó gratificante en el grupo de estudio, aunque, los cambios anatomofisiológicos pudieron afectar el disfrute pleno de los encuentros sexuales (21). Resaltamos, la existencia de innumerables 
maneras de dar y recibir placer; por tanto, no hay recetas únicas y válidas cuando hablamos de placer(2,16,17).

Se concluye que las principales prácticas eróticas en esta etapa de vida fueron el coito peneano vaginal y estimulación mutua; la postura más practicada fue "de costado", prioritariamente en el último trimestre, y el alcance del placer sexual fue mayor en el tercer trimestre. Se recomienda que los profesionales obstetras desarrollen una educación sexual en la gestante y pareja, que responda a sus reales necesidades e inquietudes para la vivencia saludable de la sexualidad.

\section{Referencias bibliográficas}

1. OMS. La salud sexual y su relación con la salud reproductiva: Un enfoque operativo [Internet]. O M S ; 2018 . D is p o n ible en: http://bit.ly/2K1r9Au

2. Sologuren, G. ¿Prohibido? ¡El placer sexual tu derecho! Primera Edición. Perú: Fondo Editorial de la UNJBG; 2018. Cap. III 65-70; Cap. IV 99-112, 127-31; Cap. XI 193.

3. Martinotti, A., Sebastiani, M. Sexualidad y Embarazo [Internet]. Intra Med. 2002 [citado 8 de noviembre de 2019]. Disponible en: http://bit.ly/36KSosY

4. Bataglia, V., Leguizamón, L., Gonzáles, L., Velgara, M. Sexualidad y embarazo: Cambios observados en la sexualidad femenina durante la gestación. 2014; 47:13.

5. Sequera M, José M. Características del ejercicio de la función sexual de las pacientes embarazadas. Consulta prenatal del H.U.A.L. octubre 2008-diciembre 2008. enero de 2009 [citado 8 de noviembre de 2019]; Disponible en: http://riuc.bc.uc.edu.ve/handle/123456789/165 9

6. Levin, A. Cambios en la actividad sexual durante la gestación [Internet] [Tesis para optar el título de Médico Cirujano]. Universidad Abierta Interamericana Sede Regional Rosario; 2012. Disponible en: http://bit.ly/2JQUG1A

7. Alonso, L., Pérez, M., Arias, C., Figueroa, N., Gamarra, C., Martinez, A., et al. Características biopsicosociales y frecuencia de relaciones sexuales de las embarazadas en la ESE Prudencio Padilla Clínica Sur. Barranquilla (Colombia). 2004;13.

8. Rodríguez-Rubio M, Coll-Navarro E, GiménezGómez N. Evolución y cambios de la sexualidad durante la gestación: visión de la mujer embarazada. :9.
9. Guibovich, A., Angulo, T., Lujan-Carpio, E. Análisis de la actividad sexual de gestantes sin riesgo obstétrico que acuden a Hospitales públicos de Lima Metropolitana, Perú [Internet]. 2015 [citado 24 de noviembre de 2019]. Disponible en: https://bit.ly/2RPAvDq

10. Panea, I, Dominguez, A., Barragan, V., Martos, A., López, F. Comportamiento y actitud frente a la sexualidad de la mujer embarazada durante el último trimestre. 2018.

11. Munares-García, O. Prácticas sexuales en gestantes peruanas. Rev Peru Investig Materno Perinat. 2018;7(2):41-5.

12. Rodriguez, M., Muñoz, R. Características de la salud sexual durante el embarazo en un grupo de mujeres de Madrid. Investigación y cuidados. 2015;13(32):19-23.

13. Johnson C. E. Sexual health during pregnancy and the postpartum. J Sex Med. 2011;8(5):26784.

14. Mederos S, Muñoz MJ. Características del ejercicio de la función sexual de las pacientes embarazadas. Consulta prenatal del H.U.A.L. octubre 2008-diciembre 2008. 2009 [citado 24 de noviembre de 2019]; Disponible en: https://bit.ly/2KkH1Oa

15. Tasso, V. Sexo 4.0 ¿Un nuevo (des)orden amoroso? Primera Edición. Barcelona: Editorial Planeta, S.A.; 2017. 109-69 p.

16. De la Cruz C. Sexualidades diversas, sexualidades como todas. Madrid: Editorial Fundamentos; 2018. 62-76, 215-21 p.

17. De la Cruz C. Sexualidades que importan. Madrid: Editorial Meridiano; 2018. 25-32 p.

18. Romero G del CT, Tavara M del SP, Macías JSZ, López ABV. Comportamiento y conducta sexual en gestantes. Rev Científica Mundo Investig El Conoc. 2019;3(2):860-81. 
19. Torres $\mathrm{G}$ del C, Palacios M del S, Zambrano JS, Vallejo AB. Comportamiento y conducta sexual en gestantes. Rev Científica Mundo Investig El Conoc. 2019;3(2):860-81.

20. Balestena, J. M., Fernández Hernández B, Sanabria Negrín JG, Fernández Alech R. Percepción de la mujer gestante sobre su función sexual. Rev Cienc Médicas Pinar Río. junio de 2014;18(3):363-74.
21. García M. R, González SánchezA, Llibre Guerra JJ, García Arjona L, Perera Boza O. Comportamiento de la conducta sexual durante el embarazo en un grupo de puérperas. Rev Cuba Obstet Ginecol. marzo de 2015;41(1):39-49.

\section{Correspondencia:}

gemasologuren5@hotmail.com
Fecha de recepción: 20 de abril del 2020

Fecha de aceptación: 28 de mayo del 2020 